\title{
The Window of Talent Policy in Regional Revitalization: For A More Socially Creative Urban Blueprint
}

\author{
-- Comparative Analysis of Talent Window between Quanzhou City, China, and Tottori Prefecture, \\ Japan and feasible solutions to promote Regional Revitalization
}

\author{
Rongmao Lin \\ Department of Culture Industry, Fujian Normal University, Fuzhou, 350007, China
}

\begin{abstract}
Talent Window is a crucial part of the Talent Policy, directly establishing communications with the talents. Today, it is generally set through the Official Service Websites, combined with various Information Publishing Platforms and Offline Service Windows, so that the talents could obtain the information about Talent Policy and consult with administrative staff about all matters related to talent introduction. The key indicator of a Talent Window is whether it could genuinely attract talent inflow and then improve urban vitality. Furthermore, the perfection and convenience of the Talent Window and its encouraging effect on talents are also the keys to whether it could bring "a sense of welcome" to them and make them willing to contribute to social creativity. Considering the significance of Talent Window in implementing Regional Revitalization, this article explores feasible solutions for setting the Talent Window based on comparing the present situation and Talent Window between Quanzhou City, China, and Tottori Prefecture, Japan.
\end{abstract}

Keywords: Regional revitalization, Talent policy, Cultural policy, Talent attraction, Urban vitality, Social creativity.

\section{Introduction}

“Regional Revitalization”(地方創生 [1]) is the general name of a series of policies put forward by the Japanese government to amend Tokyo's one pole concentration, slow down the reduction of regional population and enhance Japan's overall vitality. Fundamentally, the target of Regional Revitalization is not limited to rural areas but also includes various urban areas lacking local vitality, and mainly utilize the Cultural and Creative Industry to achieve Cultural Valueadded and economic development through the local color. Among the policies in the Regional Revitalization, the Talent Policy (地方創生人材プラン) has always been one of the most important links, and it mainly starts from the aspects of Talent Cultivation, Talent Support, and Talent Utilization [1]. The policies of Talent Support and Talent Utilization are closely related to the Talent Introduction Policy, which aims to absorb non-native talents and retain local talents through a series of beneficial policies, including technical talents and management talents from various fields like electronics, finance, culture, or art, which are all the driving forces of Regional Revitalization.

However, few previous studies focused on the window of the Talent Policy. They studied the policy contents itself rather than the communication ways of these policy contents. Hence, we proposed the concept of the Talent Window and proved its importance in Regional Revitalization.

As mentioned in the abstract, the Talent Window does not include basic contents such as Talent cultivation, Infrastructure Construction. It is like a bridge connecting policies and talents that combines online and offline communication windows, releasing essential information to the talents. After comparing the settings of the Talent Window in different regions, we summarized several detailed evaluation indicators:
Table 1. Evaluation Indicators of Talent Window

\begin{tabular}{|c|c|}
\hline Number & Indicator \\
\hline $\mathbf{1}$ & Design and Contents of the Website \\
\hline $\mathbf{2}$ & Entrance for Talent Application \\
\hline $\mathbf{3}$ & Application Process \\
\hline $\mathbf{4}$ & Offline Communication Place (Offline \\
\hline $\mathbf{5}$ & windows) \\
\hline $\mathbf{6}$ & Mechanism of Talent Recognization \\
\hline $\mathbf{7}$ & Recruitment for Functionary \\
\hline
\end{tabular}

These leading indicators are relatively accurate measurements of a Talent Window because these measurements directly determine the using feeling of the talents when they intend to stay in a city. We considered this "A sense of welcome," which has the primary and intuitive influence on Regional Revitalization. To be exact, a better setting of Talent Window could bring more "A sense of welcome" to the talents, offering a more promising blueprint of the future for them, which means more driving forces for the Regional Revitalization. Accordingly, after a period of statistics, the comprehensive data from different aspects could eventually reflect the results of this influence and the setting of Talent Window. For example, Net Inflow of talents, Output Value of High-tech industries (are all ways to examine the success of the result). Indeed, these measurements could also be further improved, and we also hope that other researchers could improve the evaluation system in the future.

The purpose of this paper is to point out several feasible solutions as helpful suggestions for the cities to set the Talent Window (Some previous studies by this research as helpful suggestions have successfully improved the Talent Window of Quanzhou and brought benefits) and bring it into the sight of relevant research on Regional Revitalization. The two main research objects are Quanzhou City, China, and Tottori Prefecture, Japan. We also analyzed their present situations in Regional Revitalization by collecting data, analyzing 
documents, and interviewing the mayor's secretary of Quanzhou City.

Before we start the comparative analysis, we need to settle a question that other researchers often ask. The question is, why did we choose to compare the two cities? Do they have any similarities? Admittedly, significant differences exist in urban scale, geographical location, social development, and other aspects between Quanzhou City, China, and Tottori Prefecture, Japan. Such differences would cause deviation when researching policy contents. Moreover, the research results may only match a specific city. However, Talent Window research is different from traditional policy researches, a similar setting of Talent Window could be used in another city despite the differences of the cities. What is more, comparisons of the two cities could better demonstrate the positive and negative results of different Talent Window settings.

\section{Comparison and Analysis of Talent Window}

\subsection{Current Situation of Regional Revitalization in Quanzhou and Tottori}

\subsubsection{Current Situation of Quanzhou, China}

As a famous historical and cultural city in China, Quanzhou has the titles of "Origin of the Maritime Silk Road" and "The City of Light." In its most prosperous period, Quanzhou was synonymous with China as "Zayton," and it was the largest seaport of the world at that time. Nowadays, this region still possesses innumerable cultural resources. On July 25, 2021, "Quanzhou: China's world marine trade center in Song and Yuan Dynasties" successfully passed the deliberation of the 44th session of the UNESCO World Heritage Committee and was successfully listed in the world heritage list.

Nevertheless, the fact is that Quanzhou still relies on manufacturing since modern times and has encountered many failures in promoting Regional Revitalization during the past few years. This research is also based on such a truth being known by local citizens that Quanzhou seriously lacks vitality and attempted to figure out problems and solutions. Undoubtedly, to ensure the rigor of this study, we conducted several social surveys and an interview with the mayor's secretary between 2020 and 2021(We did not excessively use official data published in the public because researchers studying region policies of China are all aware of the comparative lower credibility of these documents) to more accurately illustrate the problems of talents in Quanzhou and the negative impact on Regional Revitalization.

In 2017, Quanzhou Municipal government launched the "Harbor Plan [2]" to attract talents to stay in Quanzhou in order to improve social creativity. At present, 26 batches of talents have been selected, but most of the lists came from the Internal-referral by the government instead of external application. Many fundamental problems exist in the settings of Talent Window and the implementation processes of other policies in Regional Revitalization. Consequently, These problems have affected the initiative of talents, and caused the shortage of social creativity, which is why many cities are often inadequately prepared to promote Industrial Transformation and Regional revitalization. The common problems of withholding funds and formalism could also be reflected in the setting of Talent Window.

According to the latest data provided by municipal personnel of the Quanzhou government [3], the situation about a shortage of talents could be obviously seen. Firstly, Quanzhou is currently facing a shortage of 60000 technical talents. Secondly, there were 35000 college graduates in Quanzhou in 2020, of which $62.5 \%$ natives and $19.7 \%$ Nonnatives stayed in Quanzhou. Besides, most of them engaged in traditional industries rather than cultural, tourism, and entertainment industries that contribute to the Regional Revitalization. Certainly, it is also related to the sluggish development of these new industries in the region.

In a word, the Regional Revitalization of the culturally rich Quanzhou is still in its infancy.

\subsubsection{Current Situation of Tottori Prefecture Japan}

Since the government of Tottori Prefecture has not publicly released the data of talents (We believe that this is because of the only hundreds of thousands of people in Tottori Prefecture, thus residents are equivalent to talents), we measured the success of the Regional Revitalization of Tottori Prefecture through the industrial development indicators mentioned in the introduction.

While responding to the Japan Cabinet Office's Regional Revitalization, Tottori Prefecture has succeeded in becoming a popular tourist attraction with cultural resources such as seafood, animation, and natural scenes through some independent local policies, rejuvenating this small prefecture. According to the researches conducted by the Statistics Division and the Tourism Exchange Bureau of Tottori, as of 2018, the tertiary industry in Tottori Prefecture has continued to rise in the past 6 years, and the proportion of traditional manufacturing has declined [4], which means that Tottori Prefecture has realized the industrial transformation part of the Regional Revitalization. On the other hand, the severe population exodus caused by social dynamics (Population migration) since 2000 has been improved significantly, and it has been relatively stable since 2010 [5].

\subsection{Comparison Tables of Official Website of Talent Window}

\subsubsection{Overall Design}

The official website is the essential Talent Window, and Regional revitalization is inseparable from it. What is more, it decides whether it could bring "A sense of welcome" to the viewers, including the talents. In general, Quanzhou's web pages are more serious, while Tottori's are more lively. At the same time, Tottori's website incorporates a large number of local characteristics, and almost every part has its own outside links, connecting with other websites related to the Regional revitalization. On the other hand, Quanzhou's website is similar to a template website. Even after the revision in 2021, the functional perfection is less than $10 \%$ of Tottori Prefecture's. Therefore, the difference of visual effects and using feelings brought to people could be seen. 
Table 2. Overall Design of Websites Comparing Quanzhou

Tottori

\begin{tabular}{|c|c|c|}
\hline $\begin{array}{l}\text { Dedicated Offical } \\
\text { Website for Talent } \\
\text { Window }\end{array}$ & Yhttp://www.qzgccrc.com $\rangle$ & $\begin{array}{c}\text { YES } \\
\langle\text { https://furusato.tori-info.co.jp }\rangle\end{array}$ \\
\hline Comparison & $\begin{array}{l}\text { (1) A Template-style display website with official } \\
\text { government website style. } \\
\text { (2)The background is blue and white (has } \\
\text { improved in August } 2021 \text { after we provided } \\
\text { suggestions in the previous research in the first } \\
\text { half of 2021). } \\
\text { (3) Multiple links are missing, repeated, and } \\
\text { unclear (has little improved in August 2021). } \\
\text { (4) The font design is single. }\end{array}$ & 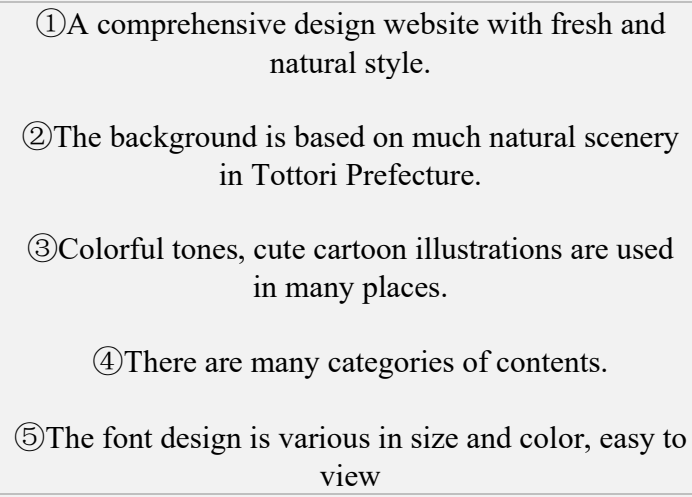 \\
\hline $\begin{array}{l}\text { Links to Tourism } \\
\text { Websites } \\
\text { (Additional) }\end{array}$ & $\mathrm{NO}$ & $\begin{array}{c}\text { YES } \\
\langle\text { https://www.tottori-tour.jp/en }\rangle\end{array}$ \\
\hline Comparison & $\begin{array}{l}\text { (1) No pages about tourism and scenery of } \\
\text { Quanzhou }\end{array}$ & $\begin{array}{l}\text { (2) The tourism website is designed with the fresh and } \\
\text { natural scenery of Tottori Prefecture, combined with } \\
\text { social media such as Instagram, YouTube, and other } \\
\text { publicity methods to arouse viewers' longings. }\end{array}$ \\
\hline
\end{tabular}

\subsubsection{Policy Contents}

Table 3. Policy Contents in Websites Comparing

\begin{tabular}{|c|c|c|}
\hline & Quanzhou & Tottori \\
\hline $\begin{array}{l}\text { Policy Contents Posted in } \\
\text { the Window }\end{array}$ & YES & YES \\
\hline Comparison & $\begin{array}{l}\text { (1) Many original policy contents, } \\
\text { but mainly opinions and general } \\
\text { plans. } \\
\text { (2) Some detailed information } \\
\text { clearly stipulates the amount of } \\
\text { subsidy. } \\
\text { (3) No PDF for particular policies. }\end{array}$ & $\begin{array}{l}\text { (1) The web pages avoid long, tedious and trivial } \\
\text { original contents of policies, and focus on } \\
\text { simple graphic layout and introductions of } \\
\text { categories. } \\
\text { (2) Specific information such as the amount of } \\
\text { housing subsidy is clear. At the same time, } \\
\text { particular policy materials are attached with } \\
\text { PDF. }\end{array}$ \\
\hline
\end{tabular}

\subsubsection{Encouraging Publicity}

Table 4. Encouraging Publicity Comparing

\begin{tabular}{|c|c|c|}
\hline & Quanzhou & Tottori \\
\hline $\begin{array}{l}\text { Dedicated Website for } \\
\text { Encouraging Publicity }\end{array}$ & $\mathrm{NO}$ & $\begin{array}{c}\text { YES } \\
\langle\text { https://furusato.tori-info.co.jp/iju/about/ }\rangle\end{array}$ \\
\hline Comparison & $\begin{array}{l}\text { (1) Several landscape carousel pictures on the } \\
\text { homepage, some information about policies, } \\
\text { industries, and community activities are posted on } \\
\text { the website. } \\
\text { (2)But the contents and the layout are relatively } \\
\text { simple, and the contents of Encouraging Publicity } \\
\text { are mainly Political Propaganda. }\end{array}$ & $\begin{array}{l}\text { (1) A dedicated web page introducing "What kind } \\
\text { of place is Tottori Prefecture" is set up, and links } \\
\text { to Tottori Prefecture's seafood sites, stargazing } \\
\text { sites, and various scenic spots sites. } \\
\text { (2) Publicize the Tottori with local characteristics } \\
\text { such as "Nature" and "Happiness," and various } \\
\text { posters in a relaxing style combined with the } \\
\text { local scenery are used. } \\
\text { (3)Concise and High-definition landscape graphic } \\
\text { banner layouts are used in many places. } \\
\text { (4)A display area of "Migrant Experience Talk" } \\
\text { is set up. At the same time, a Q\&A question } \\
\text { answering module is set up. }\end{array}$ \\
\hline
\end{tabular}




\subsubsection{Window Settings for Talent Application}

Table 5. Window Settings for Application Comparing

Quanzhou YES

Dedicated Website for Application

$\langle$ http://www.qzrc.gov.cn/talentsrv/ $\rangle$

Tottori

YES

$\langle$ https://furusato.tori-info.co.jp/iju/about/〉

\begin{tabular}{|c|c|c|}
\hline $\begin{array}{c}\text { Comparison } \\
\text { (Entrance) }\end{array}$ & $\begin{array}{l}\text { (1)The application platform is set up through the } \\
\text { official website of Talent Habour of Quanzhou } \\
\text { However, there is no entrance for talents to apply at } \\
\text { all(Still unresolved, but function for application has } \\
\text { been moved to an applet in Wechat in the second } \\
\text { half of 2021). } \\
\text { (2) The only official phone could not be } \\
\text { connected(when one member of this research finally } \\
\text { successfully connected, the receiver refused to } \\
\text { communicate and hung up quickly). }\end{array}$ & $\begin{array}{l}\text { (1) Not only for the introduction of talents, four } \\
\text { major application web windows for Migration, } \\
\text { Employment, Student Support, and Corporate } \\
\text { Support are opened. } \\
\text { (2)Multiple consultation windows, including } \\
\text { employment consultation windows, are opened } \\
\text { simultaneously, allowing E-mail, Online } \\
\text { Form Submission, Telephone Consultation, and } \\
\text { Offline Window Consultation. All kinds of } \\
\text { information are detailed, and there are many } \\
\text { built-in PDF materials for talents further to } \\
\text { understand the application steps and the } \\
\text { required preparation procedures }\end{array}$ \\
\hline $\begin{array}{c}\text { Comparison } \\
\text { (Process) }\end{array}$ & $\begin{array}{l}\text { (1) Without any concise introduction of the } \\
\text { application process, thus the talents need to find } \\
\text { specific policies themselves, the contents are also } \\
\text { unclear and abstract. }\end{array}$ & $\begin{array}{l}\text { (1) The website specially set up pages to } \\
\text { introduce related procedures of applications } \\
\text { such as Migration and Employment in Tottori, } \\
\text { which are concise and clear. }\end{array}$ \\
\hline
\end{tabular}

\subsection{Offline Windows}

It is one of the standard procedures to the operation of the Talent Window for talents to obtain information through the Internet first, and then make a consultation by a phone call or come to an Offline Window for further understanding of the local talent policies.

In addition to setting up Offline Windows in the prefecture, Tottori also set up two large Offline Windows in two developed cities, Osaka and Tokyo, and combined with Telephone Consultation. such arrangement takes full account of "U-turn” (U ターン[6]), the population return effect of developed areas.

In contrast, during the previous research in the first half of 2021, the information about Offline Windows in Quanzhou is vague, only several contact addresses are released through policy documents without specific phone numbers, or other details like those in Tottori (Thus they could not be regarded as Offline Windows). As mentioned in Table 5, we have done many investigations and found that the only telephone number on the website of Talent Window of Quanzhou is invalid, which will seriously cause talents to be unable to accurately communicate with the government and obtain more details about the Talent Policy, just as the bridge of talent policy has collapsed. Thus, one of the most important foundations for setting the Talent Window is to prevent the situation that someone could not find the access to consult.

Fortunately, after we provided suggestions, Quanzhou's Offline Window settings have been greatly improved, which will be mentioned in the following chapters.

\subsection{Talent Recognition Mechanism and Threshold}

Except for the requirements of work experience and educational background for the talents applying for functionaries, Tottori Prefecture does not set up any talent review and recognition mechanism. Instead, Tottori Prefecture has set up a system of Talent Bank to allow local companies to conduct an independent review of external talents.

On the contrary, the Quanzhou Municipal Government has proposed a Talent Recognition Mechanism and set up an online recognition window in the second half of 2021. The main targets of the Talent Recognition Mechanism are talents divided into seven levels, with a high overall threshold and specific requirements for educational background and work experience. Meanwhile, the "Talent Grading" has an appropriate relaxation of the threshold for cultural and creative talents, as well as an emphasis on the artistic talents and craftsmen. These points are all helpful to the Regional Revitalization and the development of local color.

Quanzhou and Tottori are quite different. As of 2020, the total population of Tottori is only 550,000 [7], while the population of Quanzhou is 15 times that of Tottori, and the population density is about 5 times. Due to population pressure, it is impossible to adopt the similar Talent Policy of Tottori, which has a broader threshold to talents. However, Quanzhou still has a comparatively high threshold to the talents, primarily cultural and creative talents related to Regional Revitalization, which would dampen the enthusiasm of Start-ups or entrepreneurs, since many entrepreneurs could not get the same policy support as identified talents when they are in the early stage without much awards and experience. Moreover, many past successful examples of Regional Revitalization were born under various new environments with a large number of Start-ups. For example, in Niseko Town, Hokkaido, it adopted the policy of "Support for Entrepreneurs and Business Successors”(起業者や事業継承者等に対するサポート[8]) to directly support the development of Start-ups through financial subsidies. After 5 years, 30 companies have been successfully supported and developed, and the number of visitors has increased by more than 200,000.

In conclusion, attaching importance to support for Startups and appropriately lowering the threshold are the basis for the introduction of talents, as well as for the Regional 


\section{Revitalization.}

\subsection{Recruitment for Functionary}

Tottori Prefecture has set up a particular web page for functionary recruitment on its Talent Window and other supporting websites and established an assessment system.

Regarding the recruitment of functionaries, China generally implements a selection examination, and the competition is fierce, especially in Prefecture-level cities like Quanzhou. Therefore, in the interview with the mayor's secretary, we further confirmed the shortage of functionaries in Quanzhou. In response to this problem, the Quanzhou Municipal Government adopted a system of "Temporary Functionary" to make up for the shortage of manpower. But the consequences were low efficiency and administrative imbalance in implementing policies such as Regional Revitalization and Talent policy (Could be obviously seen in the Talent Window of Quanzhou).

In such a case, it is relatively out of the scope of the research about Talent Window. Each city needs to establish a recruitment system for functionaries based on different realities. Nevertheless, from the perspective of this research, it is necessary to set up a special window for the recruitment of functionaries (Even temporary functionaries) and connect with the Talent Window.

\section{Academic Results}

The improvement of the Talent Window of Quanzhou mentioned in the above analysis was found in the second survey in August 2021. We are delighted that the mayor's secretary acknowledged the problems of the subordinate officers and adopted some of the suggestions we gave from the previous study. But there are still many climbing spaces for improvement, and we hope that further improvements could be made in the future (As described above).

First of all, the design and contents of the Official Website of Quanzhou Talent Window have been improved, and many links have been revised, but there are still some problems (Please refer to section 2.2.1 and Table 2).

Secondly, another significant improvement is that the government of Quanzhou has set up a small Program-version of the Talent Window on Wechat (A Chinese SNS), named "Talent Home", which provides functions such as Talent Recognition and queries about site of Offline Windows (In our previous research, these functions on the website were invalid).

Lastly, we hope that this research could help more cities to set up Talent Windows like this.

\section{Conclusion}

At the end of this study, the following feasible solutions are given for the establishment of a Talent Window that can maximize the promotion of Regional Revitalization.

First, regional governments should set thresholds for introducing and recognizing talents in accordance with local characteristics. At the same time, specific policies should be introduced to lower the threshold for talents related to Regional Revitalization, and attention should be paid to startups rather than eager to introduce successful ones.

Second, the setting of the online Talent Window and related websites should be complete, convenient, and easy to operate so that the recruited object (Talents) can quickly and accurately obtain all kinds of information. Also, the design of web pages needs to make people comfortable and warm, and should be given regional characteristics, combined with sightseeing elements. Undoubtedly, the contents of Encouraging Publicity should also be designed to be full of a sense of Beautiful-life and vitality by combining the above elements to arouse talents' longings for this city.

Third, The Talent Window needs to be kept open at all times. Offline Windows needs to disclose specific contact information to the public, and application entrances such as Telephone Consultation, Online Email, Social Networking Software, and Online Online Form Submission should also be set up. In addition, different windows could be set up according to local needs. For example, Tottori Prefecture set up a particular web page for fishery practitioners.

Fourth, the government should plan for creative tourism projects with regional and cultural characteristics and make a tourism website for publicity, connecting with the Talent Window. On the one hand, it directly promotes the development of the tourism industry. On the other hand, it realizes the dual-window docking for tourism and talents, which flawlessly connects the Industrial Transformation and Talents Demand required for Regional Revitalization.

Fifth, as an additional conclusion, we suggest that researchers should consider the political system of the regional government in advance when studying related topics and inquiring about official information because it would affect the credibility of these data (It could also be judged from whether it is contradictory with other data from other aspects). For instance, some regional governments do not allow negative data published in public, but apparent contradictions would be exposed in other aspects of the industry and society.

Finally, we have to point out that this research only focused on the overall setting of the Talent Window and gave feasible solutions for planning, which means it has some limitations. While some detailed indicators are not specific enough, related research topics such as "How to rationally use talents to promote Regional Revitalization, "Social creation for Regional Revitalization", "Cultural policies of Regional Revitalization and the sense of identity of residents" remain. However, we believe these issues would be further studied and successfully help the regions implement Regional Revitalization.

\section{References}

[1] Cabinet Office of Japan. "Town / People / Work Creation Long-term Vision, Comprehensive Strategy, Basic Policy." Last modified June 18, 2021. https://www.chisou.go.jp/sousei/mahishi_index.html

[2] The Quanzhou Municipal Committee of the Communist Party of China. "Several Opinions on the Implementation of the Talent Harbor Plan." February 17, 2017. http://www.qzgccrc.com/content/201702/17/content 5630455.htm

[3] Quanzhou Municipal Government. "Report on the Investigation of Talents Issues in Quanzhou.” April, 2017. Unpublished (Internal documents).

[4] Reiwa New Era Creation Headquarters Statistics Division of Tottori Prefecture. "Accounting-GDP of Citizens and Prefectural Obtains of Tottori Prefecture." February, 2021. https://www.pref.tottori.lg.jp/secure/1236428/kenminkeizai_h $30 \_$result.pdf

[5] Reiwa New Era Creation Headquarters Statistics Division of Tottori Prefecture. "Estimated Population of Tottori Prefecture 
(Annual Report, 2019 to 2020)." October 30, 2020. https://www.pref.tottori.lg.jp/secure/1225868/pe_R0110R0209_result.pdf

[6] Yuji Esaki. "U-turn Movement of People from Rural Areas." Population Problem Research 63(2), 2007, 1-13

[7] Reiwa New Era Creation Headquarters Statistics Division of Tottori Prefecture. "Estimated Population of Tottori Prefecture (Annual Report, 2019 to 2020).” October 30, 2020. https://www.pref.tottori.lg.jp/secure/1225868/pe R0110R0209_result.pdf

[8] Cabinet Office of Japan. "Introducing Examples of Regional Revitalization: Niseko Town, Hokkaido.” 2016. https://www.chisou.go.jp/sousei/case/chihou_sousei/ijyu_jirei -1.pdf 